\title{
SYNTHESIS AND BIOPHYSICAL TESTING OF A NOVEL PYRROLE- CONTAINING POLYAMIDE-BENZAMIDINE HYBRID
}

\author{
Mark Turlington, ${ }^{\mathrm{a}}$ Hilary Mackay, ${ }^{\mathrm{ac}}$ Caleb Rutledge, ${ }^{\mathrm{a}}$ Zarmeen Taherbhai, ${ }^{\mathrm{a}}$ Binh Nguyen, ${ }^{\mathrm{b}}$ \\ David Wilson, ${ }^{b}$ Moses Lee ${ }^{* \mathrm{a}, \mathrm{c}}$ \\ Moses.Lee@furman.edu \\ "Department of Chemistry, Furman University, Greenville, SC 29613 \\ bepartment of Chemistry, Georgia State University, Atlanta, GA 30303 \\ ${ }^{\mathrm{c}}$ Current address: Hope College, Science Center 2000, 35E $12^{\text {th }}$ St., Holland, MI 49422
}

\begin{abstract}
This communication details the rationale for the design of a novel polyamide molecule, 1 , in which the standard dimethylamino $\mathrm{C}$-terminus functionality has been replaced with a benzamidine moiety. The synthesis of this molecule and the subsequent DNA binding properties, determined from surface plasmon resonance and DNA melts are reported. The benzamidine moiety was shown to significantly increase the binding affinity of the polyamide to its cognate AATTT sequence compared to the parent $\mathrm{C}$-terminus compound $\mathbf{2}$.
\end{abstract}

\section{Introduction}

Since the discovery of the minor groove binding small molecules netropsin and distamycin (Figure 1), and the characterization of their ability to selectively bind AT-rich sequences in DNA, many polyamide analogs have been designed and investigated for their binding and biological properties.' The rationale for the design of these analogs comprises three objectives. First, analogs are devised with the intention of increasing the binding specificity of the molecule to its target DNA sequence, improving the ability to recognize and differentiate between AT and GC base pairs. ${ }^{2-4}$ The increase in specificity ensures that the drug interacts with and affects primarily its intended target sequence, as opposed to indiscriminately interacting with the DNA. Furthermore, it has been shown that compounds demonstrating the highest sequence specificity also often demonstrate the highest cytotoxicity. ${ }^{5}$ Secondly, analogs are designed to demonstrate strong binding affinity, ${ }^{4}$ in order to strengthen the ligand-DNA interaction. Finally, and most importantly, analogs are designed that suggest the potential of biological activity, such as anticancer, antimicrobial, or antiviral affects, with the intention of future medicinal applications. Much work to design and study biologically active minor groove binders capable of sequence specificity and binding strength has already been completed, yet a great deal of potential remains in this field for the discovery of medicinally useful molecules. ${ }^{1}$

Equally promising as biologically active small molecules are the furamidines, another class of minor groove binding molecules shown to target AT-rich sequences in DNA. ${ }^{6}$ Most notably, furamidine (Figure-1) and its derivatives have been reported to possess antimicrobial properties, specifically against Pneumocystis carinii, a pathogen causing pneumonia largely in infants and AIDS patients, ${ }^{6,7}$ and against Trypanosoma rhodesience, a parasite associated with the African Sleeping Sickness. ${ }^{B}$ Currently, a furamidine prodrug is undergoing Phase II clinical trials for these two diseases. Additionally, furamidine and its analogs possess anticancer properties, demonstrating cytotoxicity against a variety of tumor cell lines. ${ }^{10}$

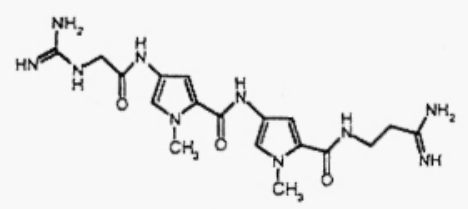

netropsin

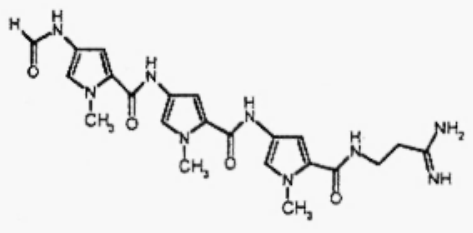

distamycin

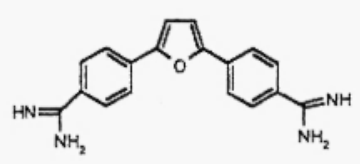

furamidine

Figure-1: Structures of netropsin, distamycin, and furamidine.

This paper reports the synthesis and biophysical testing of a novel heterocyclic compound 1 . This compound represents a bridging of the above two classes of minor groove binding molecules. The 
design of hybrid 1 takes advantage of the widely demonstrated sequence specificity and strong binding capabilities of its polyamide portion, in combination with the known biological activity of its benzamidine portion. This approach, utilizing the polyamide portion of the molecule as a sequence specific delivery system of a biologically active functionality, has been frequently applied with success. $^{2}$ Furthermore, previous research reports that the combination of biologically active compounds with polyamides often increases the molecule's overall activity. ${ }^{5}$ Currently, tests are being planned to evaluate the biological activity of compound 1 against the Trypanosomas. A polyamide structure consisting of pyrrole heterocycles was selected due to their preference for ATrich sequences. ${ }^{4}$ This AT sequence preference is shared by the benzamidine moiety. ${ }^{6}$

Moreover, the advantages of the structural design were intended to be two-sided. Not only was the polyamide structure designed to help direct the benzamidine moiety to its target in the minor groove, but the benzamidine functionality was intended to increase the polyamide's strength of binding to DNA as well as its solubility in water. This design was based on previous research, which demonstrated that the amidine terminal group assists nuclear uptake of furamidine analogs in cells. This enhanced uptake was proposed to be the result of strong binding of the drug to the DNA, facilitated by the benzamidine group.' To test the enhanced binding affinity potentially conferred upon the polyamide by the benzamidine moiety, compound 2 was also synthesized (Scheme-1). Here the novel benzamidine C-terminus functionality was replaced with the standard and well-researched dimethylamino moiety. This dimethylamino C-terminus group has become a benchmark for polyamide molecules due to its chemical stability, ease of synthesis, purification, and handling, and similar binding properties to the amidinium tail found in distamycin., ${ }^{3,1}$

\section{Results and Discussions}

The synthesis of novel compound 1 was successfully completed according to Scheme-1. Following a procedure reported by Creary, ${ }^{12}$ nitrobenzamidine 3 was prepared by reacting 4 -nitrobenzonitrile with sodium methoxide overnight, followed by heating the solution at $43{ }^{\circ} \mathrm{C}$ for four hours in the presence of ammonium chloride. Following the reduction of compound 3 under $\mathrm{H}_{2}$ in the presence of $5 \% \mathrm{Pd} / \mathrm{C}$ and methanol, the aminobenzamidine intermediate was coupled to the dipyrrole carboxylic acid in the presence of EDCI and DMAP in dry DMF. Compound 1 was worked up by ethyl acetate, hexane, and dichloromethane washes, and further purified by silica gel column chromatography. Compound 2 was synthesized by previously reported methods. ${ }^{13}$ The structures of compounds 1 and 2 were determined by analysis of their $500 \mathrm{MHz}{ }^{1} \mathrm{H}-\mathrm{NMR}, \mathrm{FT}-\mathrm{IR}$, and mass spectrometry data.

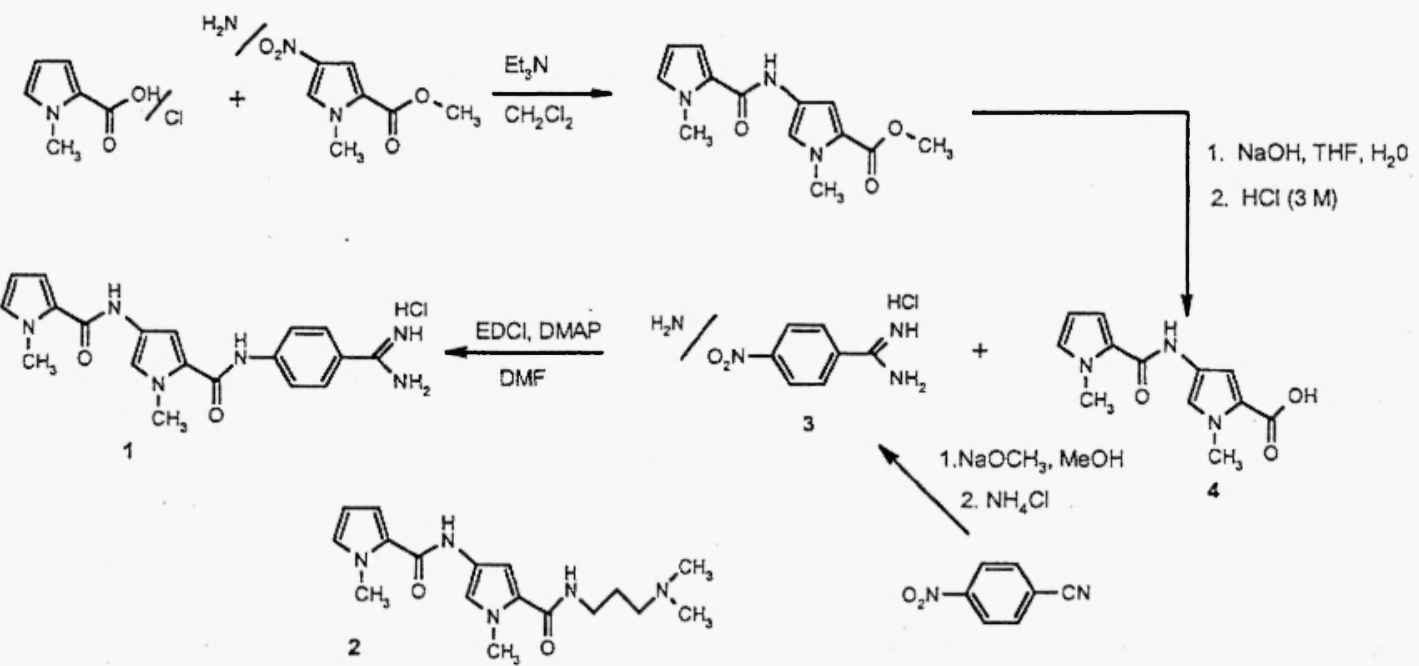

Scheme-1. Synthetic pathway for preparation of 1 and structure of control compound 2. 
Upon synthesis, compounds 1 and 2 were investigated by a series of biophysical tests, such as DNA melting $\left(\Delta \mathrm{T}_{\mathrm{M}}\right)$. The polyamide-benzamidine hybrid 1 showed strong binding to poly $(\mathrm{dA})$.poly $(\mathrm{dT})$, demonstrating substantial $\Delta T_{M}$ values, especially as the ratio of compound to DNA base pairs was increased. The thermal melting studies were conducted on a Cary 100 spectrophotometer, with a Peltier variable temperature holder. The experiments were performed using a buffer that was made up of $0.006 \mathrm{mM} \mathrm{NaCl}, 1 \mathrm{mM}$ EDTA, $10 \mathrm{mM}$ MES buffer, and with $1 \mu \mathrm{M}(\mathrm{bp})$ poly(dA).poly(dT) and the appropriate amount of compound. These results are displayed in Table-1. Compound 2, however, demonstrated poor DNA binding, with $\triangle T_{M}$ values of less than $1{ }^{\circ} \mathrm{C}$ for its cognate sequences, $5^{\prime}$ CGAAATTTCCCTCTGGAAATTTCG-3' and 5'-CGGAATTCCCCTCTGGGAAT-TCCG-3'. This compound's lack of binding was not surprising, as it has previously been reported that polyamides with three heterocycles exhibit the strongest binding properties, whereas compounds with two heterocycles display greatly reduced binding. ${ }^{13,14}$

Table-1: $\Delta \mathrm{T}_{\mathrm{M}}$ values for 1 .

\begin{tabular}{|l|l|}
\hline Compound 1/DNA (base pair ratio) & $\Delta \mathrm{T}_{M}$. \\
\hline 0.25 & 4 \\
\hline 0.5 & 10 \\
\hline 1 & 16 \\
\hline
\end{tabular}

The DNA interaction properties of benzamidine containing polyamide 1 were further investigated by surface plasmon resonance (SPR) in which the binding constant could be determined. Based on the best fit of the sensorgrams, the kinetics of association and dissociation were obtained, and from these values the binding constant was calculated to be $8 \times 10^{5} \mathrm{M}^{-1}$. The SPR studies were conducted at 25 ${ }^{\circ} \mathrm{C}$ in a $10 \mathrm{mM}$ MES buffer containing $0.1 \mathrm{M} \mathrm{NaCl}$ and $1 \mathrm{mM}$ EDTA for the following two DNA sequences: 5'-CGAATTTCGTCTCCGAAATTCG-3' and 5'-GCAATTTGCTCTCGCA-AATTGC3'. These equilibrium constant values are comparable to the tripyrrole polyamide (Figure-2), reported to be $1.2 \times 10^{5} \mathrm{M}^{-1}{ }^{15}$ Thus, it is apparent that the benzamidine $\mathrm{C}$-terminus modification significantly enhances the binding affinity of compound 1 .

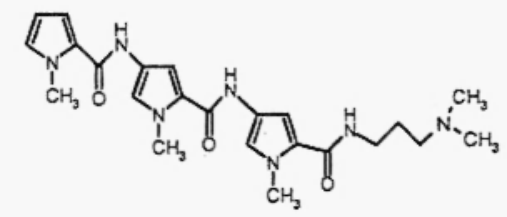

Figure-2: Structure of tripyrrole polyamide.

\section{Experimental}

Benzamidine $3 .^{12}$ Sodium $(1.68 \mathrm{mg}, 0.073 \mathrm{mmol})$ was added to distilled methanol $(0.073 \mathrm{~mL})$ to obtain $1 \mathrm{M} \mathrm{NaOCH}$. The $1 \mathrm{M} \mathrm{NaOCH}$ was then added to 4-nitrobenzonitrile $(0.1 \mathrm{~g}, 0.676 \mathrm{mmol})$ stirring in methanol $(3 \mathrm{~mL})$. The mixture was gently warmed to dissolve the remaining solid and the solution was allowed to stir overnight. $\mathrm{NH}_{4} \mathrm{Cl}(0.036 \mathrm{~g}, 0.686 \mathrm{mmol})$ was added, and the reaction mixture was heated in an oil bath at $43^{\circ} \mathrm{C}$, stirring overnight. The solution was cooled and the small amount of precipitate present in the reaction mixture was removed by Buchner funnel. The filtrate was concentrated by rotary evaporation. The yellow solid was triturated with acetone to dissolve the unreacted benzonitrile. The precipitate was collected via Buchner funnel, rinsing with additional acetone. The resulting yellow powder was dried in the vacuum desiccator $(136 \mathrm{mg}, 70 \%)$.

Compound 1. Nitrobenzamidine $(0.095 \mathrm{~g}, 0.469 \mathrm{mmol})$ was reduced by catalytic hydrogenation for 1.5 hours by stirring in cold methanol under $\mathrm{H}_{2}$ atmosphere with $5 \% \mathrm{Pd} / \mathrm{C}(0.010 \mathrm{~g}, 10 \%$ by wt.). The resulting amine was filtered through Celite and rinsed with methanol. The methanol was removed by rotary evaporation and the amine was co-evaporated $3 x$ with distilled dichloromethane. The amine 
was dissolved in DMF ( $5 \mathrm{~mL})$ and DIPEA $(0.022 \mathrm{~mL}, 0.127 \mathrm{mmol})$ was added. Dipyrrole carboxylic acid $4(0.19 \mathrm{~g}, 0.796 \mathrm{mmol})$, EDCI $(0.367,1.91 \mathrm{mmol})$, and $\operatorname{DMAP}(0.016 \mathrm{~g}, 0.131 \mathrm{mmol})$ were combined in dry DMF $(5 \mathrm{~mL})$. The amine was added dropwise and the solution was left to stir over the weekend. The solution was concentrated under reduced pressure $\left(0.1 \mathrm{~mm} \mathrm{Hg}, 80^{\circ} \mathrm{C}\right)$ on a Kugelrohr apparatus. The resulting oil was then rinsed with ethyl acetate, hexane, and dichloromethane, decanting the solvent. The washes removed some of the impurities present. The product was further purified by silica gel column chromatography, using a methanol and chloroform solvent system, eluting to $60 \%$ methanol. The product eluted between $40 \%$ and $50 \%$; a yellow orange solid $(0.076 \mathrm{~g}, 40.4 \%)$ that decomposes at $295^{\circ} \mathrm{C}$; TLC $\left(20 \% \mathrm{MeOH} \mathrm{CHCl}_{3}\right) \mathrm{R}_{\mathrm{f}} 0.1$; IR (neat) 3395 , 2924, 2362, 1711, 1460, 1377, 1165, 725; 'H-NMR (DMSO, $500 \mathrm{MHz}) 9.77$ (s, 1H), 8.15 (d, 2H), $7.85(\mathrm{~s}, 1 \mathrm{H}), 7.38(\mathrm{~s}, 1 \mathrm{H}), 7.29(\mathrm{~s} 1 \mathrm{H}), 7.11(\mathrm{~s}, 1 \mathrm{H}), 6.94(\mathrm{~d}, 2 \mathrm{H}), 6.92(\mathrm{~s}, 1 \mathrm{H}), 6.06(\mathrm{~s}, 1 \mathrm{H}), 5.81(\mathrm{~s}$, $4 \mathrm{H}), 3.93(\mathrm{~s}, 3 \mathrm{H}), 3.88(\mathrm{~s}, 3 \mathrm{H})$. TOF-MS-ES $\mathrm{m} / \mathrm{z}$ (relative intensity): $365\left(\mathrm{M}+\mathrm{H}^{+}, 15\right)$.

\section{Acknowledgments}

We thank the NSF-REU and the Jean Dreyfus Boissevain Undergraduate Scholarship for their support.

\section{References}

1. C. Bailly and J.B. Chaires, Bioconjugate Chem. 9, 513 (1998).

2. L.H. Hurley, J. Med. Chem. 32, 2027 (1989).

3. M. Lee, A.L. Rhodes, M.D. Wyatt, M. D'Incalci, S. Forrow and J.A. Hartley, J. Med. Chem. 36, 863 (1993).

4. K.L. Buchmueller, A.M. Staples, C.M. Howard, S.M. Horick, P.B. Uthe, N.M. Le, K.K. Cox, B. Nguyen, K.A.O. Pacheco, W.D. Wilson and M. Lee, J. Am. Chem. Soc. 127, 742 (2005).

5. M.D. Wyatt, M. Lee, B.J. Garbiras, R.L. Souhami and J.A. Hartely, Biochemistry 34, 13034 (1995).

6. I.J. Simpson, M. Lee, A. Kumar, D.W. Boykin and S. Neidle, Bioorg. \& Med. Chem. Lett. 10, $2593(2000)$.

7. A. Lansiaux, L Dassonneville, M. Facompre, A. Kumar, C.E. Stephens, M. Bajic, F. Tanious, W.D. Wilson, D.W. Boykin and C. Bailly, J. Med. Chem. 45, 1994 (2002).

8. B.P. Das and D.W. Boykin, J. Med. Chem. 20, 531 (1977).

9. M. Anbazhagan and D.W. Boykin, Heterocyclic Commun. 9, 117 (2003).

10. S. Neidle, L.R. Kelland, J.O. Trent, I.J. Simpson, D.W. Boykin, A. Kumar and W.D. Wilson, Bioorg. Med. Chem. 7, 1403 (1997).

11. J.S. Taylor, P.G. Schultz and P.B. Dervan, Tetrahedron 40, 457 (1984).

12. X Creary, A.F. Sky and G. Phillips, J. Org. Chem. 55, 2005 (1990).

13. M. Thomas, U. Varshney and S. Bhattacharya, Eur. J. Org. Chem. 21, 3604 (2002).

14. M. Lee, A.L. Rhodes, M.D. Wyatt, M. D'Incalci, S. Forrow and J.A. Hartley, Biochemistry 32, 4237 (1993).

15. E.R. Lacy, N.M. Le, C.A. Price, M. Lee and W.D. Wilson, J. Am. Chem Soc. 124, 2153 (2002).

Received on December 16, 2005 